\title{
Smart City Concept for Integrated Citizen Information Smart Card or ICISC in DKI Jakarta
}

\author{
Muhammad Syarif Hartawan ${ }^{1}$, Arman Syah Putra ${ }^{1}$, Ayub Muktiono ${ }^{1}$ \\ ${ }^{1}$ Universitas Krisnadwipayana \\ ${ }^{1}$ STMIK Insan Pembangunan \\ ${ }^{1}$ Universitas Krisnadwipayana \\ Email: muhammadsyarif@unkris.ac.id
}

\begin{abstract}
.
The development of cities that adopt smart is very much around the world, many cities in the world have developed the concept of a smart city in all aspects of life from identity to law enforcement systems in the traffic sector, smart cities have begun to be implemented in the city of Jakarta from 2000 onwards, Starting from the online payment system to the use of CCTV in law enforcement in the city of Jakarta, almost all aspects of government have used the system, from absences to public service applications, in this study using the literature review method, by studying many previous studies in order to deepen research that is is being carried out and finding renewable research problems, this research will produce a proposed system that can be used in the future as a concept for the development of a smart city Jakarta, with the proposed system as renewable research from existing research.
\end{abstract}

Keyword: Smart City, Citizen, Smart Card, DKI Jakarta.

\section{INTRODUCTION}

Smart cities are cities that have integrated information and communication technology with the aim of improving people's welfare. Smart city is established because of two processes that work in parallel, namely social and technical processes. There are 3 processes that must work together, namely scientific and technological progress, the desire to improve the quality of life and the use of innovative resources. The three processes must work together to create new social values and good urban development. However, because of that, making a smart city could mean that making a smart city only needs a unique technology.

In fact, making a smart city should consider various aspects. And in this paper these aspects are considered by providing smart city benchmark results to serve as benchmarks for a successful smart city. Smart city benchmarks include Smart Economy, Smart Living, Smart Government, Smart People, Smart Mobility and Smart Environment. This smart city benchmark can be developed based on the criteria and characteristics of the needs of urban residents, which are different from one city to another. Research is carried out from a systematic point of view by experts. The data obtained later can be a tool for making smart cities [15]. 
In this study the authors raised the problem of the relationship between smart cards that can be connected to all parties, such as ID cards, Driver Lisence, MRT cards and many others, this research produces a system proposal that can be applied to the Pinta city system in Jakarta, with this proposed system. then the smart city of Jakarta will soon be realized, all systems will be connected and will be able to make it easier for people to take care of things $[12,13,14]$.

There are 10 success factors in making Barcelona a smart city, namely: anticipating challenges in the 21 st century, namely rapid population growth, considering technology as a facilitator not an end in itself, securing strategies as an ambitious city change project, determining a long-term vision, defining plans defining local challenges, establishing comprehensive action plans and cross-sectoral approaches, aligning strategies with existing funding frameworks and schemes, engaging citizens in processes, ensuring an efficient governance model and integrating all key stakeholders, building alliances: industrial and economic partnerships [1].

In the development of a smart city, there are services that must be provided, namely the technology used for this development and sufficient scope. The drawbacks and strengths of smart cities have been identified and a model for designing a smart city architecture is proposed. There are 3 cases for this smart city. The first is the conceptualization of the smart city architecture, namely the provision of basic services for a smart city that must be provided in various regions and the technology that must exist. The second is technology support that can be used at many different levels to provide optimal solutions to specific problems. The third is a proposed global architecture for managing multiple services in smart cities. To achieve this, architecture must be self-adapting [2].

Evaluates 20 successful smart cities that can be used for better urban development. The 20 cities are: Bangkok, Berlin, Bodo, Buenos Aires, Canberra, Chicago, Delft, Dubai, Hague, Helsinki, Honk Kong, Johannesburg, Malmo, Melbourne, Moscow, New York, Singapore, Songdo / Incheon, Toronto, Wellington. The evaluation results show that the most comprehensive smart city is in Songdo, South Korea. The key to evaluating smart cities lies in Smart Economy, Smart Living, Smart Government, Smart People, Smart Mobility and Smart Environment. Smart Economy has indicators: job opportunities, productivity, local and global linkages. Smart Living has indicators: health, safety, culture and happiness. Smart Government has indicators: online services, infrastructure, open government. Smart People have indicators: education, an inclusive society, creativity. Smart Mobility has indicators: mixed access to capital, clean and non-motorized mobility, integrated ICT. Smart Environment has indicators: smart buildings, resource management, urban planning [3].

Storm Cloud is how to transfer data quickly using large data storage, with the cloud it will make sending data easier because it can be done anywhere and anytime, storm cloud systems are made for fast large storage [4].

The PV system or photovoltaic system is a buoyancy system that can integrate into conventional power generation systems. India wants to implement a floating solar PV system with a capacity of 100 $\mathrm{kWp}$ has been proposed for Lake Loktak, Manipur. Another 1MW pilot project at the Meenkara dam in Palakkad district and plans to set up a $50 \mathrm{MW}$ floating solar power plant project in Kerala [5].

The four major cities in Europe (Amsterdam, Barcelona, London and Stockholm) have their respective strategies in terms of the use of sophisticated economics, human and social capital development, environmental development and pro-business networks. First city Amsterdam, Netherlands. To make it the smart city of Amsterdam with the ultimate goal of reducing CO2 emissions. The two cities 
of Barcelona, Spain. To make it a smart city Barcelona uses a formal strategy of having a global outlook, seeking to establish an open environment for collaboration between government, industry, academia and citizens. Third London. To make it a smart city London focuses mostly on the institutional and digital space, rather than the physical. Finally the city of Stockhoml, Sweden. To make it a smart city Stockholm uses a strategy. The strategy is citizen-centric, focused on providing improved e-government services to citizens [6].

How development of industrial applications for satellite systems to provide the ability to run civil systems with the aim of developing cities to demonstrate that a city that is driven has a quality of life and safety for its citizens. The target to be achieved in this system is extensive experimental validation of unit scenarios [7].

Smart cities are simultaneously based on the development of systems based on research, research that is developed by the government, all systems are based on research for government development, and all analysis and technicality are based on issues from the government for the development of systems in government, and the system must be applied to the system in government [8].

Smart cities have aspects that become weaknesses, namely: Formation of a smart city approach as a technical or technological solution and a strong emphasis on technology or communication. Lack of emphasis on transforming governance and exploring the organization of smart forms of urban governance in this case using ICT Lack of smart city management standards for different types of cities, new cities, cities reconstructed, etc. This problem can be solved based on the principles of an integrated approach with the participation of various specialists in the fields of management science, urban planning, organizational design, creating a new conception of city management and forming a new model of smart city government structure [9]. The main challenges of Smart City are definition, scope and interconnection. Several different examples of implementing Smart City vary from the field of Information and Communication Technology to the use of Big Data for more accurate decision making [10].

The idea of Smart Cities is a major part of how cities face difficulties in reaching the future. This study proposes a new framework for optimizing the use of ICT as part of the solution to a problem. The proposed framework aims to redefine the Smart City paradigm by focusing on the three pillars of metabolism, culture and governance. Metabolism provides a better understanding of the technology breakthroughs that have recently emerged. In doing so, the proposed framework provides an alternative vision of Smart Cities that go beyond ICT, enabling them to become part of the values cities need to create their future [11].

As population levels continue to increase in cities this will continue with additional increases in levels of pollution, scarcity of resources, traffic, etc. Cities today face new economic, political and technological responsibilities that must be fulfilled to provide welfare for their citizens. Social, Management, Economics, Law, Technology and Sustainability (SMELTS) can be considered as important factors affecting smart cities and a clear study of these will help understand smart city issues [12].

\section{METHOD}

At this stage, it discusses the research methods used in this research, with the right method it will make the research easier and a clear research flow, while the pictures and explanations of the research methods can be seen below: 


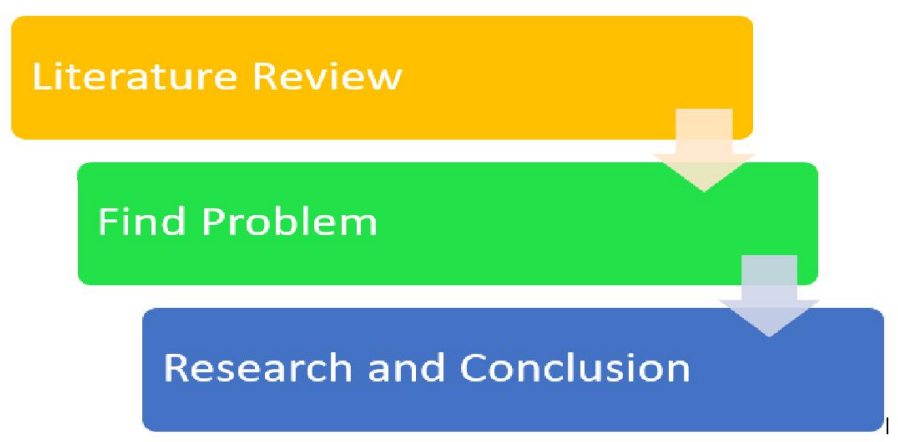

Figure 1. Research Metodology

Based on the picture above, an explanation will be given below, as for the explanation as follows:

1. Literature ReviewAt this stage, conducting a literature review, by reading many supporting journals that have conducted previous research and supporting books as a handbook, will deepen the knowledge that is being researched and will find new research problems.

2. Find ProblemsAt this stage, look for problems and what this research will produce, by finding renewable problems, it will be the basis of reference for future research.

3. Research and ConclusionAt this stage, doing research to solve existing problems, with the results of the research it will answer the problems raised in this study.

\section{RESULT AND DISCUSSION}

With the rapid advancement of the components of the smart city, it is not impossible that something unthinkable will just happen. Smart cities are synonymous with big data, therefore the use of integrated cards for the masses will be very useful. Where, this card will contain many useful things that make it easier for the smart city community [16].

The card referred to here is a card that contains information from residents who live in the smart city. The information referred to is such as ID Card, Driver Lisence, health card and others into one card. With all that together, residents don't have to carry too many cards anymore. Simply by scanning the barcode on the card, our identity and residence documents will appear [17,18]. Not only containing identity, this card can be filled with balances for transportation in the smart city. Residents can use this card to pay for the public transportation they use. Not only to pay for transportation but also to shop at supermarkets in the city. In other words, this card can also be used as a debit or credit card.

This card will also be useful for government. With data that has been integrated, the government will find it easier to record the population when needed. Because this card contains owner information including disease information from the owner of this card. With that, when residents go to the hospital, they can easily get information on the resident's previous illness by simply scanning the barcode on the card.To scan this barcode, you don't need a special tool, just a smartphone or other device that has software installed to read the card. And what is certain for stored data is general data these residents. Data that is too personal is adjusted to the rights of the population [19].

The creation of this card requires a smart city with 6 components, namely: Smart Economy, Smart Living, Smart Government, Smart People, Smart Mobility and Smart Environment. 
The way this card works is explained in the flowchart below:

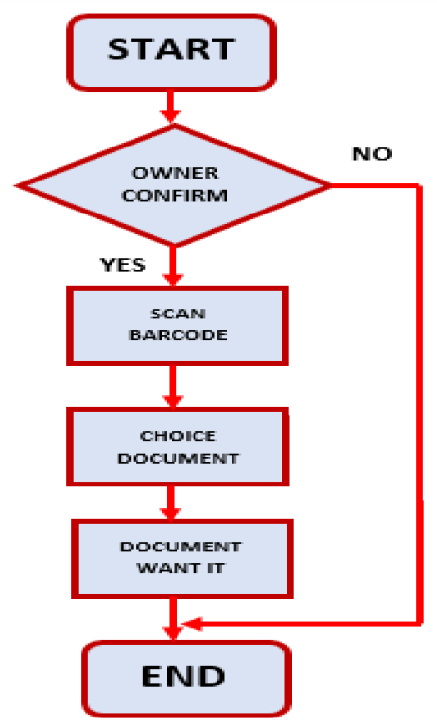

Figure 2. Flowchat Card

Before the barcode on the card is scanned, confirmation will be made by the card owner, confirmation can be a fingerprint or password configured by the card owner. If you do not agree, it will not be scanned and if you agree, it will be scanned by the officer / resident to select which document will be shown. If you have selected which document will be displayed, the document will appear on the device used by the officer / resident.

The models of the cards mentioned above are as follows:

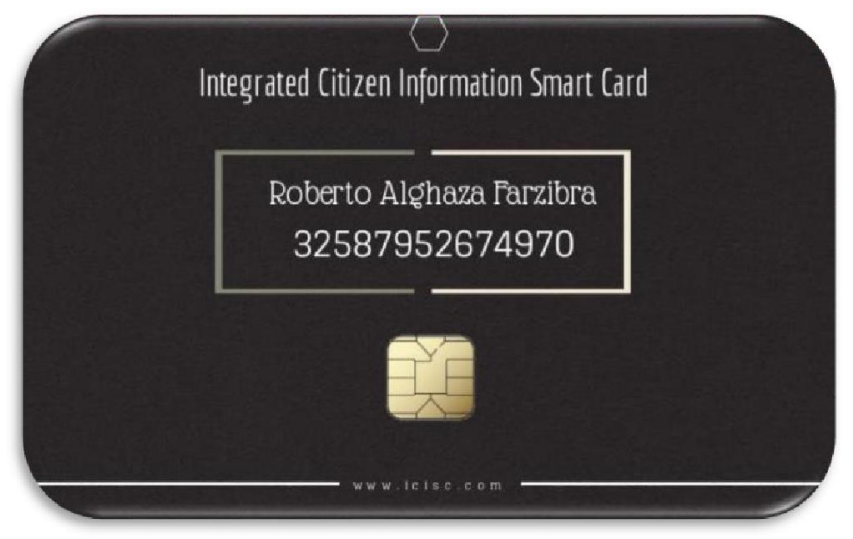

Figure 3. Integrated Citizen Information Smart Card or ICISC looks Front 


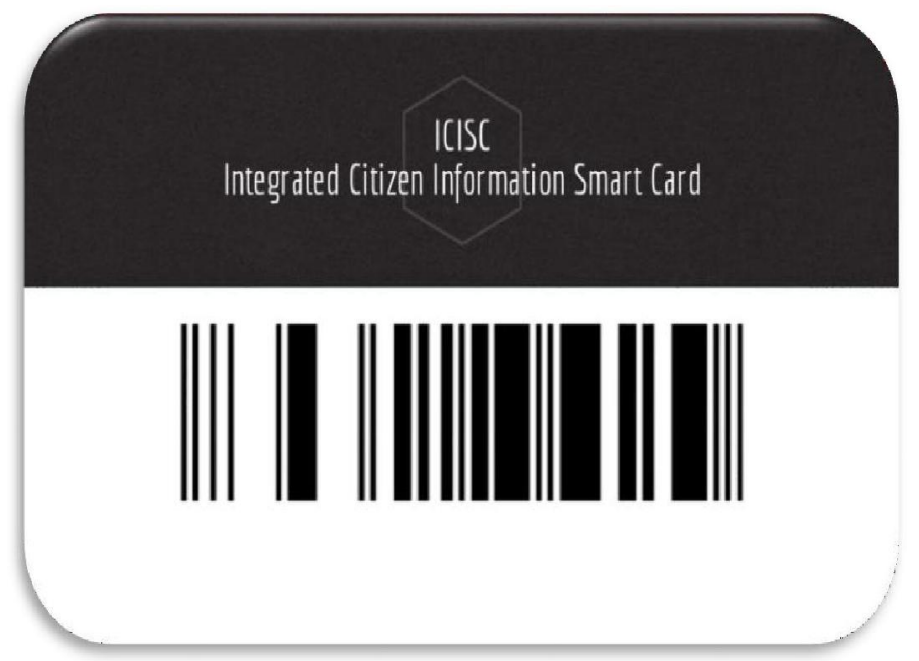

Figure 4. Integrated Citizen Information Smart Card or ICISC looks Back

So for the front card design only information about the name of the resident of the city and their residence number. As for the back, only barcodes are displayed for shopping at supermarkets or seeking treatment at the hospital. The name of the card itself is Integrated Citizen Information Smart Card or ICISC for short.

\section{CONCLUSION}

Smart cities are cities that have integrated information and communication technology with the aim of improving people's welfare. A smart city is also arguably an efficient, technologically advanced, green and socially inclusive city. This means that smart city applications place a specific technology focus at the forefront of generating solutions to ecological, social, economic and management challenges. There are 3 processes that must work together, namely scientific and technological progress, the desire to improve the quality of life and the use of innovative resources. The three processes must work together to create new social values and good urban development. The main challenges of Smart City are definition, scope and interconnection.

The idea of Smart Cities is a major part of how cities face difficulties in reaching the future. This study proposes a new framework for optimizing the use of ICT as part of the solution to a problem. The proposed framework aims to redefine the Smart City paradigm by focusing on the three pillars of metabolism, culture and governance. The smart city benchmark itself covers Smart Economy, Smart Living, Smart Government, Smart People, Smart Mobility and Smart Environment. This smart city benchmark can be developed based on the criteria and characteristics of the needs of urban residents, which are different from one city to another.

Further research can re-develop programs that have been made or that have not been made in order to improve the benchmark of smart cities based on the criteria and characteristics of urban needs. Requires a role big to make it a more successful smart city to support society.

\section{REFERENCES}

[1] Josep Ramon Ferrer. "Barcelona's Smart City vision: an opportunity fortransformation”. Institut Veolia. 2017.

[2] Pablo Chamoso, Alfonso González-Briones, Sara Rodríguez, JuanM. Corchado. "Tendencies of Technologies and Platforms in Smart Cities: A State-of-the-Art Review". BISITE Digital Innovation Hub. 2018.

[3] Lyudmila Vidiasova, Polina Kachurinaa, Felippe Cronembergerb. "Smart Cities Prospects from the Results of 
the World Practice Expert Benchmarking". Elsevier B.V. 2017.

[4] Kakderi C, Komninos N and Tsarchopoulos P. "Smart cities and cloud computing: lessons from the STORM CLOUDS experiment". Whioce Publishing. 2016.

[5] Singh A K, Boruah D, Sehgal L, et al. "Feasibility study of a grid-tied 2MW floating solar PV power station and e-transportation facility using 'SketchUp Pro' for the proposed smart city of Pondicherry in India". Whioce Publishing. 2016.

[6] Angelidou Margarita. "Four European Smart City Strategies". Redfame Publishing.2016.

[7] Casciati F, Casciati S, Faravelli L and Vece M. "Framing a satellite based asset tracking (SPARTACUS) within smart city technology". Whioce Publishing. 2016.

[8] Meijer Albert and Manuel Pedro Rodr1'guez Bolı'var. "Governing the smart city: a review of the literature on smart urban governance". Regional Development Publisher. 2018.

[9] LogvinovValerii and Natalia Lebid. "Is the Smart cities of hybrid model of local government - The type III cities: Four possible answers". Procedia Computer Science. 2016.

[10] Allam Zaheer and Peter Newman. "Redefining The Smart City: Culture, Metabolism and Governance". MDPI Pubisher. 2018.

[11] Sanseverino Eleonora Riva, Raffaella Riva Sanseverino, and Enrico Anello. "Across-Reading Approach to Smart City: A European Perspective of Chinese Smart Cities”. MDPI Pubisher. 2018.

[12] Serrano Wil. "Digital Systems in Smart City and Infrastructure: Digital as a Service". MDPI Pubisher. 2018.

[13] Rathore M. Mazhar, Anand Paul,Awais Ahmad, Gwanggil Jeon. "IoT- Based Big Data: From Smart City towards Next Generation Super CityPlanning". International Journal on Semantic Web and Information Systems. 2017.

[14]Trindade Evelin Priscila, Marcus Phoebe Farias Hinnig, Eduardo Moreira daCosta,JamileSabatiniMarques,RogérioCidBastosandTanYigitcanlar. "Sustainable development of smart cities: asystematic review of the literature". Open Innovation: Technology, Market, and Complexity.2017.

[15] Winters John V. "Why Are Smart Cities Growing? Who Moves And Who Stays". Journal Of Regional Science. 2017.

[16] A. S. Putra and L. H. S. W. Harco, "Intelligent Traffic Monitoring System (ITMS) for Smart City Based on IoT Monitoring," Indonesian Association for Pattern Recognition International Conference (INAPR) IEEE, pp. 161-165, 2018.

[17] A. S. Putra, "Penerapan Konsep Kota Pintar dengan Cara Penerapan ERP (Electronic Road Price) di Jalan Ibu Kota DKI Jakarta. Jurnal Informatika Universitas Pamulang, 5(1), 13-18.," Jurnal Informatika Universitas Pamulang, 5(1), 13-18., pp. 13-18, 2020.

[18] A. S. Putra, " "Smart City : konsep Kota pintar di DKI Jakarta"," Jurnal TEKINFO, Vol 20, No 2, Hal 1-111, ISSN 1411-3635, 2019.

[19] M. S. Hartawan, I. Mantra and I. W. Widi Pradnyana, "Interpretative Analysis and Testing Statistics to test questions testing the Mobile Government questionnaire against the model of readiness and successful adoption," 2019 International Conference on Informatics, Multimedia, Cyber and Information System (ICIMCIS), Jakarta, Indonesia, 2019, pp. 147-150, doi: 10.1109/ICIMCIS48181.2019.8985195. 